Received: 31 January 2018

Accepted: 2 May 2018

Published online: 30 May 2018
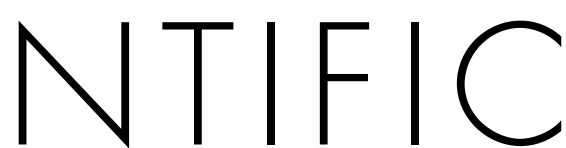

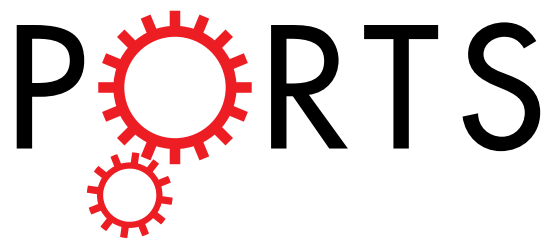

\title{
OPEN Identification of a peptide for folate receptor alpha by phage display and its tumor targeting activity in ovary cancer xenograft
}

Lijun Xing ${ }^{1}$, Yifeng X ${ }^{1}$, Keyong Sun ${ }^{1}$, Hong Wang ${ }^{1}$, Fengguo Zhang ${ }^{1}$, Zhengpin Zhou ${ }^{1}$, Juan Zhang ${ }^{1}$, Fang Zhang ${ }^{2}$, Bilgen Caliskan ${ }^{1}$, Zheng Oiu ${ }^{1}$ \& Min Wang ${ }^{1}$

The expression level of folate receptor alpha (FR $\alpha)$ is located highly rate in ovarian cancer though it is remained absent in normal tissues. This highly tumor restricted expression profile makes FR $\alpha$ a promising target for tumor therapy and diagnosis. In this research we report a FR $\alpha$ binding peptide C7(Met-His-Thr-Ala-Pro-Gly-Trp-Gly-Tyr-Arg-Leu-Ser) discovered by phage display and this peptide showed specific binding to FR $\alpha$ expressing cells by cell ELISA and flow cytometry. Tumor targeting ability of C7 was proved in vivo by both phage homing experiment and fluorescence imaging. C7 can be internalized by SKOV 3 cells and its affinity to FR $\alpha$ was determined by MST. The molecular recognition was revealed by structure modeling, suggesting its binding mode with FR $\alpha$.

Folate receptor alpha $(\mathrm{FR} \alpha)$ is a $38-\mathrm{kDa}$ glycosylphosphatidylinositol (GPI)-anchored glycoprotein that binds physiological folates and mediates their intracellular transport ${ }^{1}$. It is found that FR $\alpha$ expression in normal tissues is highly restricted to the apical surface of polarized epithelial cells and moreover it is inaccessible to the normal circulation $^{2}$. FR $\alpha$ is significantly up-regulated in a variety of epithelial cancers such as serous and endometrioid epithelial ovarian cancer (OC), endometrial adenocarcinoma, non-small cell lung cancer (NSCLC) of the adenocarcinoma subtype, and to a less extent in clear cell renal, colorectal and breast cancers to meet the folate demand of rapidly dividing cells under low folate conditions ${ }^{3-5}$. In nearly $90 \%$ of the non-mucinous ovarian cancer, FR $\alpha$ expression has been observed and correlated with tumor grade, stage, aggressiveness and its expression is maintained after chemotherapy in epithelial ovarian and endometrial cancer ${ }^{6,7}$.

FR $\alpha$ can be exploited for cancer diagnostics and treatments ${ }^{8}$. A range of FR $\alpha$-targeting approaches, including folic acid derivatives, folate drug-conjugates and small molecules, vaccines, T-cell therapies and monoclonal antibodies (mAbs), have been developed for both imaging and therapeutic purposes ${ }^{9-12}$. Monoclonal antibodies can bind specifically to FR $\alpha$ with high affinity. Although various anti-FR $\alpha$ antibodies have been generated and investigated, the clinical results were not successful. Farletuzumab, a humanized monoclonal antibody targeting FR $\alpha$, showed a substantial efficacy in both preclinical and Phase I/II clinical studies, whereas no improvement in progression-free survival (PFS) was observed in Phase III clinical trial ${ }^{13,14}$. Furthermore, the large molecule weight of antibody causes difficulties in tumor infiltrating and large scale manufacture. In addition to that, the Fc region of the antibodies binds to the reticuloendothelial system, resulting in significant toxicities to liver, bone marrow, and spleen. Preclinical studies of anti-FR $\alpha$ TS inhibitors including CB300638 and ONX-0801 have demonstrated anti-tumor effect in FR $\alpha$-expressing tumors ${ }^{15,16}$. However, those inhibitors could reduce folic acid transportation through reduced folate carrier (RFC), which is ubiquitously expressed, leading to non-specific effect which is related with reductions in patient tolerability ${ }^{15,16}$. It is clarified that affinity of folate for FR $\alpha$ is significantly high regarding to the interactions between the receptor and ligand. The folate pteroate moiety is buried inside the receptor, whereas its glutamate moiety is solvent-exposed and sticks out of the pocket entrance ${ }^{17}$. This binding mode allows folate to be conjugated to drugs without adversely affecting FR $\alpha$ binding. Various folate conjugates have been developed for tumor therapy and imaging. However, as summarized by Cheung ${ }^{8}$, folate 
conjugates have several disadvantages. Firstly, folate conjugates target both FR $\alpha$ and the functional form of FR $\beta$. Unfortunately, it was also possible to target infiltrated tumor-associated macrophages (TAMs), known to express FR $\beta$ without selectivity. Secondly, the binding of folate conjugates might be competitively-inhibited by excess serum free folate. Thirdly, folate conjugates could be taken up by RFC, which is expected to confer patient toxicity.

Considerably, the tumor restricted distribution of FR $\alpha$ and its emerging roles in cancer development make it a potential target especially for ovarian cancers. Novel approach has to be developed upon this tumor marker. As drug candidates, synthetic peptides have higher specificity than small molecule drugs. While comparing with antibodies, peptides have reduced immunogenicity, rapid blood clearance, increased diffusion and tissue penetration, chemical stability and ease of synthesis ${ }^{18}$. Widespread use of targeted therapies in the clinic requires high affinity, tumor-specific agents as effective targeting vehicles to deliver therapeutics to the tumor sites. Several peptides have already been used for tumor targeting and treatments. Tumor targeting peptides are efficient vehicles for selective delivery of high dose of chemotherapeutic drugs or diagnostic agents to tumor sites while sparing normal tissues. And till now there are few researches of FR $\alpha$ targeting peptides. Peptide phage display is a powerful method in discovering specific binding sequences with diverse targets like proteins ${ }^{19}$, enzymes ${ }^{20}$, virus ${ }^{21}$, cells $^{22}$, tissues or organs $s^{23}$ and provides a wide range of application possibilities in drug discovery. Therefore, we conduct a research in order to discover FR $\alpha$ binding peptides using phage display.

\section{Results}

Screening and Identification of FR $\alpha$ Binding Peptides. A Ph.D.-12 phage library displaying random dodecapeptides was used to isolate FR $\alpha$ binding phages with four rounds of biopanning. Phage yields from each round were used to indicate the enrichment of phages. After each round of biopanning, the bound phages were eluted and elutes were tested by phage ELISA to evaluate the affinity to FR $\alpha$. It was demonstrated by phage yield and polyclonal phage ELISA that the FR $\alpha$-binding phages increased as the biopanning rounds increased in the first three rounds screening, indicating that the FR $\alpha$ binding phages were enriched effectively in biopanning process (Fig. 1A and B). Phage recovery and ELISA value did not increase after the fourth round of screening, suggesting 3 rounds of panning were sufficient for FR $\alpha$ binding phages enrichment. From the third round selection, 94 phage clones were randomLy picked and their binding affinities for FR $\alpha$ were analyzed individually using phage ELISAs. All of the selected phage clones showed higher FR $\alpha$-binding affinity than did the wild-type M13 clone (Fig. 1C). Among the phage clones analyzed, 20 clones with the highest absorption values were sequenced to determine the amino acid sequences of the displayed peptides (Table 1). Several clones were found identical and totally 15 different clones were identified.

Binding to FR $\alpha$ Expressing Cells. Since prokaryotic recombinant human FR $\alpha$ protein were used for screening, the 15 selected phage clones were further tested for their binding ability to native human FR $\alpha$ expressed on the mammal cell surface. Firstly, the presence of FR $\alpha$ expression on SKOV 3 cells (human epithelial ovarian cancer cell) and the absence of FR $\alpha$ expression on HepG2 cells (human liver hepatocellular carcinoma Cells) were confirmed by flow cytometry (Fig. 2A and B). SKOV3 cells were used as positive cells and HepG2 cells were used as negative cells in the following experiments. Cell-based ELISA was used to evaluate preliminarily the binding properties of phage clones. As shown in Fig. 2C, most selected phages had a higher binding to SKOV3 cells comparing with the binding to HepG2 cells. M13KE, as the negative control, did not bind to either of the cell. 4 phage clones (C7, B8, G12, G8) with the highest binding to SKOV3 and relatively low binding to HepG2 in cell-base ELISA were selected and further evaluated by flow cytometry. In contrast to M13KE, these four clones revealed specific binding $(51.2 \%, 31.8 \%, 41.8 \%$ and $36.0 \%)$ to SKOV3 cells (Fig. 3).

C7 Phage Clone Homes SKOV3 Implanted Tumor in Vivo. To test the tumor homing efficacy, $2 \times 10^{6}$ SKOV3 cells were subcutaneously injected into the left flank of Balb/c nude mice to generate epithelial ovarian cancer xenografts. When the tumors reached about $200 \mathrm{~mm}^{3}$, the control phage M13KE or purified phage clone (C7) with superior binding ability to SKOV3 cells were injected intravenously and circulated for 15 min. After perfusion, the tumor and main organs were harvested and bound phages were recovered and quantified by phage titration. As shown in Fig. 4, C7 showed significant enrichment in tumor tissue, which was 49-fold more than the M13KE phage in tumor. And the phage titer of C7 in tumor was 190-fold higher than which in the normal ovary. Same amount of phages $\left(2 \times 10^{11}\right)$ were used in different groups and the capsid proteins were the same among different phage clones. Therefore, it was the displayed peptide that resulted in different affinities to tumors. According to the homing test, $\mathrm{C} 7$ processes tumor targeting ability in vivo.

C7 peptide binds to SKOV3 cells through FR $\alpha$. To determine whether C7 peptide targets FR $\alpha$ on SKOV3 membrane, we employed RNA interference to knockdown FR $\alpha$ in SKOV 3 cells. SKOV 3 cells were transfected with FR $\alpha$ specific siRNA and the silencing effect was confirmed with anti-FR $\alpha$ antibody using flow cytometry. It was observed that expression of FR $\alpha$ was greatly diminished in SKOV3 cells after FR $\alpha$ specific RNA interference (Fig. 5A,B). FITC conjugated peptide C7 was synthesized and tested for its binding to SKOV3 cells and the effect of RNA interference on its bind ability. C7 peptide showed a binding of $51.9 \%$ to SKOV3 cells and it was decreased significantly to $30 \%$ by FR $\alpha$ specific RNA interference, indicating C7 peptide binds to SKOV3 cells through FR $\alpha$ (Fig. 5C,D).

Tumor Targeting of Synthesized Peptide by Fluorescence Imaging. FITC conjugated peptide was injected intravenously into a tumor-bearing nude mouse to assess whether the C7 peptide retained tumor targeting capability in vivo. After $2 \mathrm{~h}$ circulation, fluorescence imaging was used to detect MFI (mean fluorescence intensity) of FITC in tumor and other organ tissues. As shown in Fig. 6, the fluorescence signal observed in the tumor is significantly stronger compared to that in other organs except liver and kidney. MFI of C7 in tumor was 
A

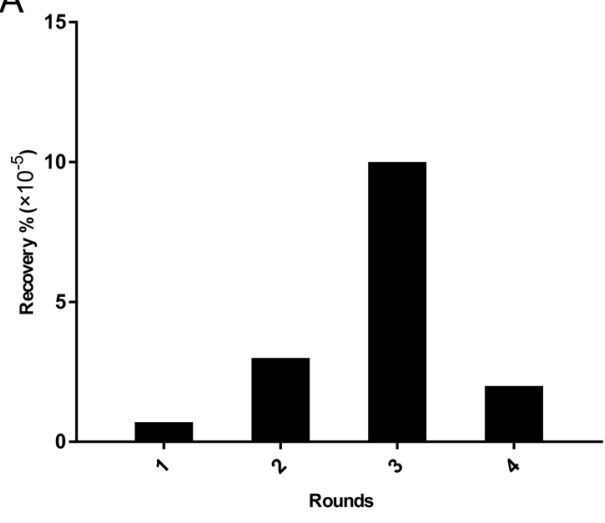

C

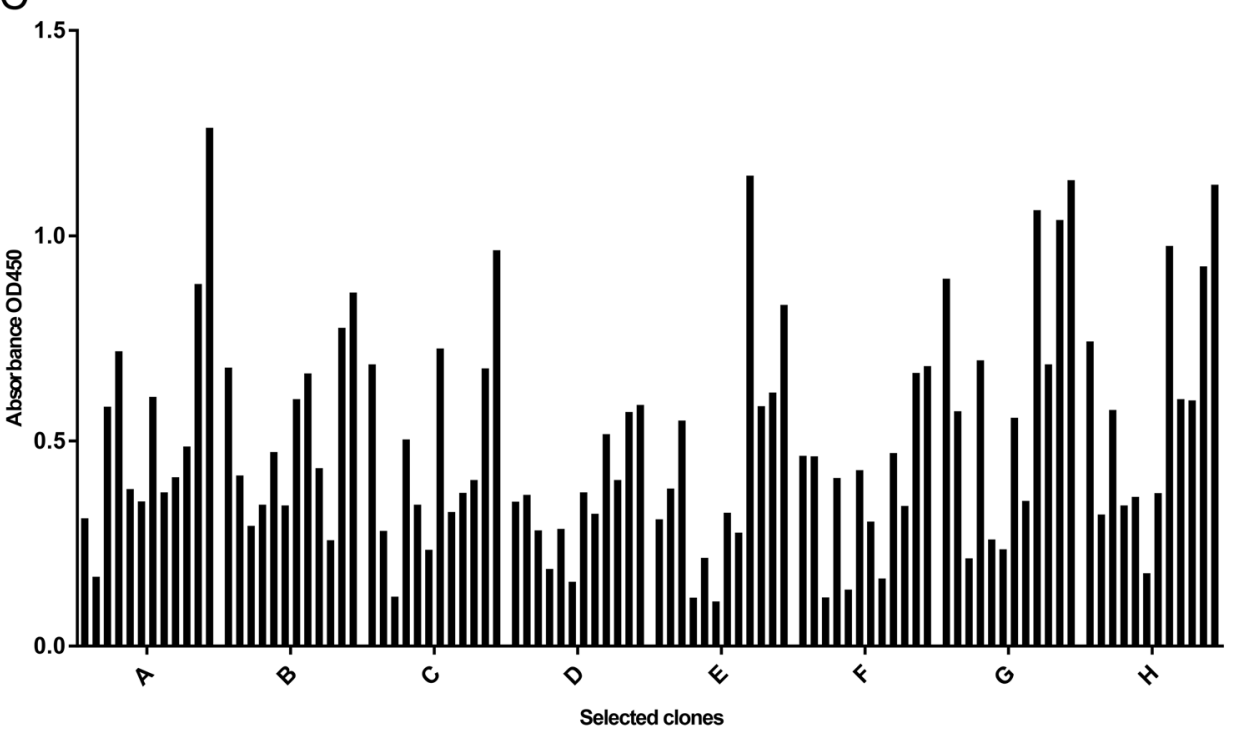

B

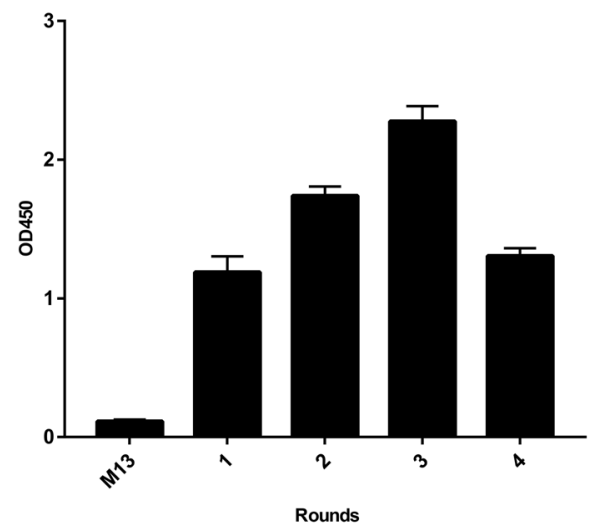

Figure 1. Screening and identification of FR $\alpha$ binding peptides. A Ph.D.-12 phage library was used to screen FR $\alpha$ binding phages with four rounds of biopanning. (A) The enrichment of FR $\alpha$ binding phages were evaluated by phage recovery yields of each round selection. (B) Polyclonal phage ELISA using elutes after each round selection. (C) 94 phage clones were randomLy picked from the third round selection, and their binding affinities for FR $\alpha$ were analyzed individually by phage ELISA.

detected to be 3.3 times stronger than that in ovary. Thus, it has been demonstrated that the synthesized peptide C7 maintains tumor targeting activity in vivo.

Peptide has High Affinity for FR $\alpha$. MST Analysis was performed in furtherance of evaluating binding affinity of C7 for FR $\alpha$. According to the changes of fluorescent thermophoresis signal caused by the serial dilutions of labeled peptides, the equilibrium dissociation constant $(\mathrm{KD})$ value was calculated from Hill formula by the NT analysis. It was showed that the equilibrium dissociation constant (KD) value between $\mathrm{C} 7$ and $\mathrm{FR} \alpha$ was $0.3 \mu \mathrm{M}$ (Fig. 7).

Cell Internalization of Synthesized Peptide. FITC conjugated peptide C7 or FITC conjugated irrelevant peptide (PB-TUP) was incubated with SKOV3 cells for 4 hours at $37^{\circ} \mathrm{C}$. After fixation, confocal microscopy was used to visualize the internalization of peptide into SKOV3 cells. In addition, HepG2 cells were used to evaluate the internalization of peptide C7 into FR $\alpha$ low expressing cells. As shown in Fig. 8, the florescence can be observed in the cytoplasm and at the perinuclear region, showing the peptide C7 can be internalized into SKOV3 cells. In contrast, irrelevant peptide was not internalized by SKOV3 cells, and C7 peptide was not detected in HepG2 cells.

Circular Dichroism Spectroscopy Analysis. To analyze the secondary structure of the peptide C7, we performed CD spectroscopy. The CD spectrum of C7 exhibited a minimum at $198 \mathrm{~nm}$ and a maximum at $220 \mathrm{~nm}$, demonstrating a random coil structure of the peptide (Fig. 9). The results of molecular modeling supported the formation of random coil structure (Fig. 10A). Peptide secondary structures are key determinants of molecular 


\begin{tabular}{|l|l|}
\hline Clones & Peptide Sequence \\
\hline A3 & Leu-Gly-Ile-Ser-Ala-Thr-Asn-Ala-Tyr-Ala-Arg-His \\
\hline A4 & Phe-Ser-Gln-Ala-Thr-Gly-Arg-Ser-Pro-Thr-Thr-Leu \\
\hline A7 & Ala-Ser-Val-Leu-Asp-Tyr-Lys-Gly-Phe-Phe-Gln-Arg \\
\hline A12 & Thr-Ala-Ala-Gln-Trp-Phe-Pro-Ser-Leu-Ser-Asn-Asn \\
\hline B1 & Asn-Trp-Gln-Pro-Thr-Ala-Gly-Leu-Lys-Pro-Leu-His \\
\hline B7 & Trp-Ser-Ala-Ala-Thr-Val-Pro-Arg-Gly-Phe-His-Ala \\
\hline B8/H1/G4 & Gly-Ala-Leu-Leu-Pro-Ser-Met-Asn-Lys-Gly-His-Trp \\
\hline C1 & Ser-Asn-Ser-Asp-Ala-Tyr-Ala-Leu-Gln-Phe-Leu-Arg \\
\hline C7 & Met-His-Thr-Ala-Pro-Gly-Trp-Gly-Tyr-Arg-Leu-Ser \\
\hline E9 & Phe-Phe-Pro-Leu-Thr-Phe-Pro-Trp-Thr-Tyr-Tyr-Asp \\
\hline G1/G10 & Ser-Gly-Val-Tyr-Lys-Val-Ala-Tyr-Asp-Trp-Gln-His \\
\hline G9, D5 & Val-His-Trp-Asp-Phe-Arg-Gln-Trp-Trp-Gln-Pro-Ser \\
\hline G8 & Tyr-Thr-Asn-Pro-Tyr-Tyr-Ser-Ser-His-Thr-Arg-Asn \\
\hline G12 & Met-Asn-Pro-Tyr-Pro-Arg-Thr-Pro-Trp-Pro-His-Val \\
\hline H11 & Arg-Gly-Met-Asp-Thr-Leu-Trp-His-His-Ala-Tyr-His \\
\hline
\end{tabular}

Table 1. Peptide sequences of phage clones binding to FR $\alpha$ in random twelve peptide library. 20 clones with the highest ELISA abortion values were sequenced to determine the amino acid sequences of the displayed peptides. 15 clones with individual peptide sequence were identified.

A

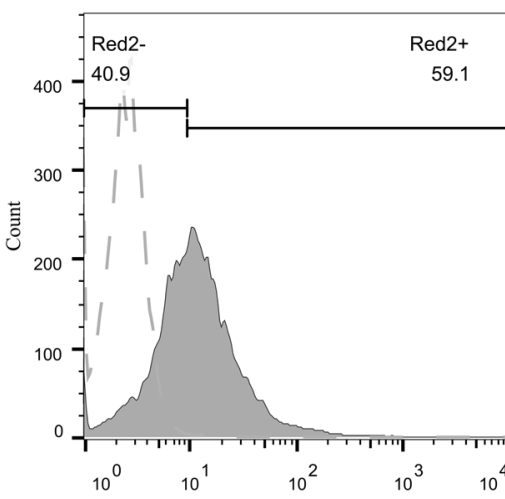

$\mathrm{CON}$
B

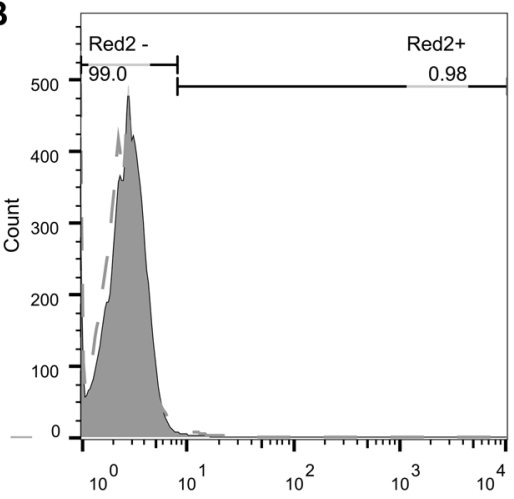

FR $\alpha$ antibody

C

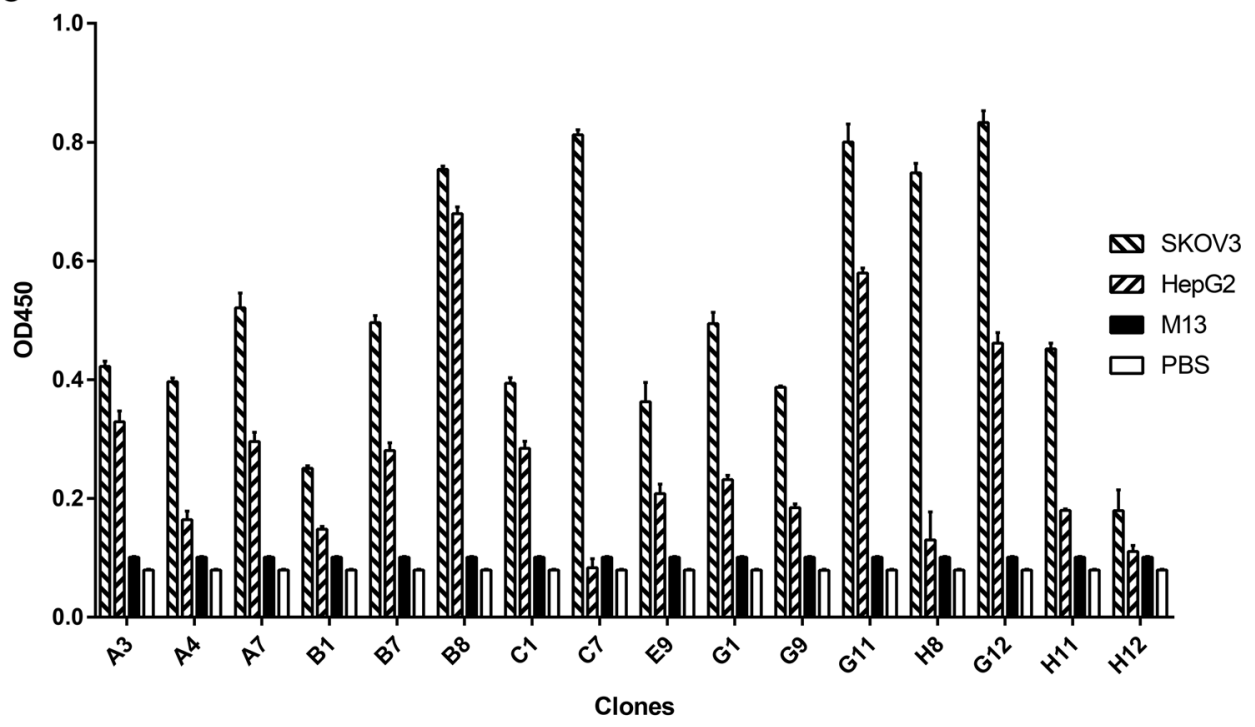

Figure 2. Phage binding to FR $\alpha$ expressing cells. SKOV3 and HEPG2 were tested for their FR $\alpha$ expression by flow cytometry and used as positive and negative cells in cell ELISA. (A) The expression of FR $\alpha$ on SKOV 3 cells. (B) The absence of FR $\alpha$ expression on HEPG2 cells. (C) Phage clones were further screened by cell ELISA. 

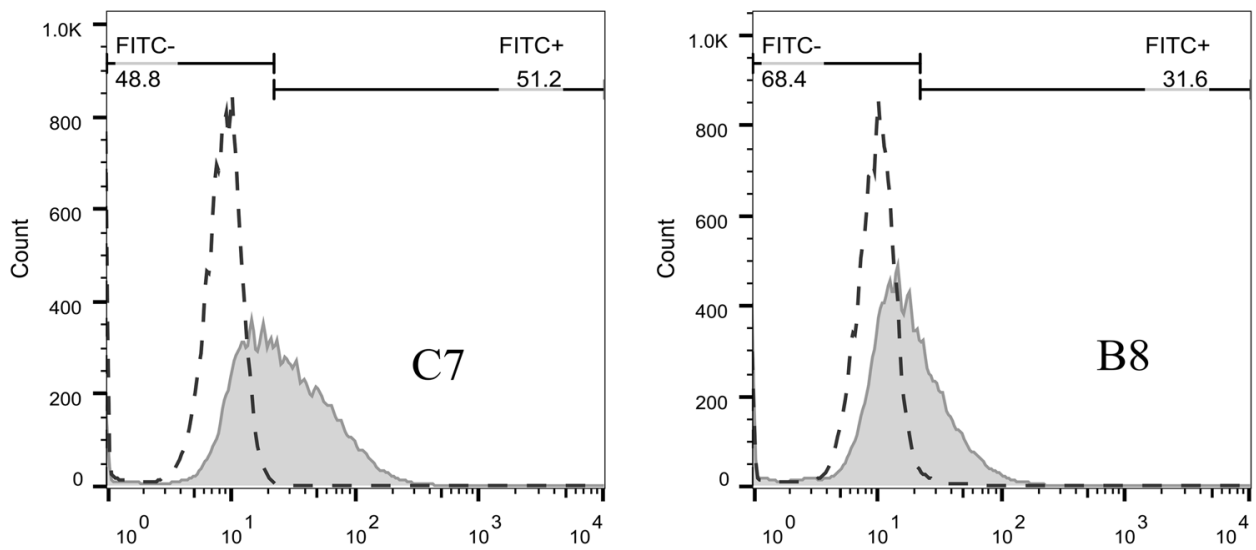

GRN-HLog :: Green Fluorescence (GRN-HLog)

GRN-HLog :: Green Fluorescence (GRN-HLog)
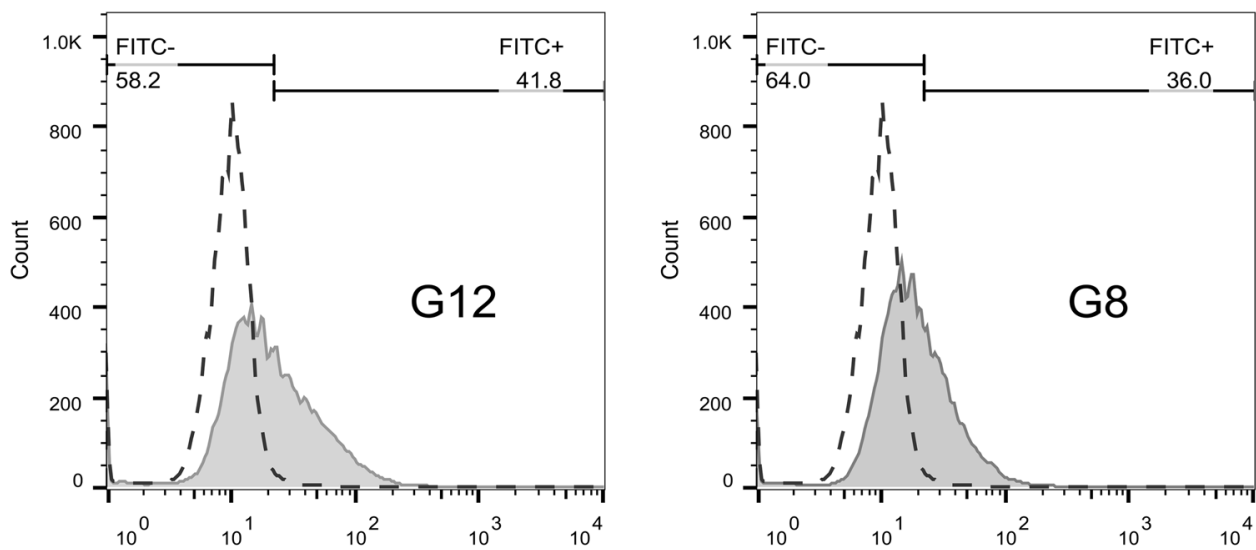

GRN-HLog :: Green Fluorescence (GRN-HLog)

$$
\text { - - - - - M M13 }
$$

GRN-HLog :: Green Fluorescence (GRN-HLog)

\section{Phage colony}

Figure 3. Phage binding to SKOV3 cells was confirmed by flow cytometry. Four phage clones (C7, B8, G12, G8) revealed specific binding $(51.2 \%, 31.8 \%, 41.8 \%$ and $36.0 \%)$ to SKOV3 cells. Phage M13 was assessed as negative control.

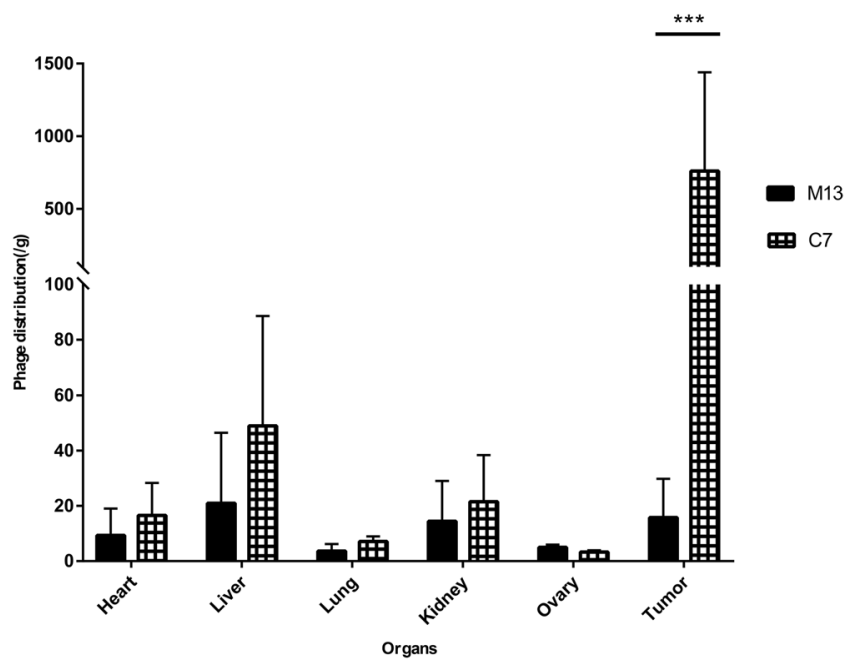

Figure 4. In vivo homing of the selected phages in SKOV3 xenografts. Selected phage clones C7, or M13KE phage were amplified and $2 \times 10^{11}$ individual purified phage clones were injected intravenously to tumor bearing mice. The distribution of phage in tumor and normal organ tissues was determined by titration. Results were expressed as titrated phages per gram of tissue. Data were given as the mean $\pm \mathrm{SD}(\mathrm{n}=3)$. 


\section{SKOV3}
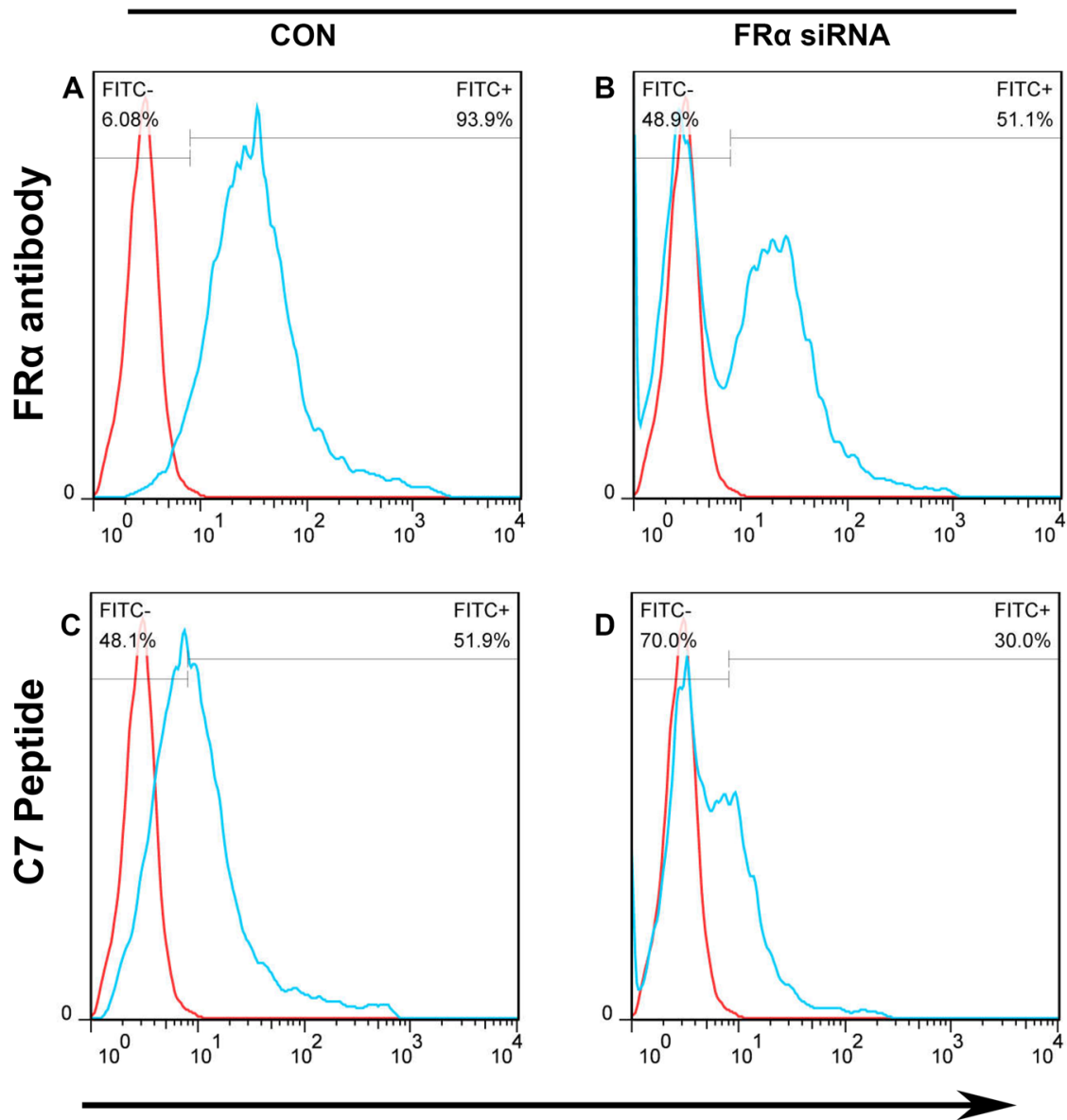

\section{Log fluorescence}

Figure 5. RNA interference diminished the binding rate of $\mathrm{C7}$ peptide to SKOV3 cells. SKOV3 cells were transfected with FR $\alpha$ specific siRNA or control siRNA. After $72 \mathrm{~h}$, siRNA mediated silencing of FR $\alpha$ was tested with monoclonal anti-FR $\alpha$ antibody. It was shown that the expression of FR $\alpha$ was decreased from $93.9 \%$ to $51.1 \%$. The binding of C7 peptide to SKOV3 was reduced from $51.9 \%$ to $30 \%$ after FR $\alpha$ knockdown.

interactions. Random coil structure makes the peptide highly flexible and this structure might help the peptide optimize the arrangement of amino acid residues in binding with FR $\alpha$.

Computational Modeling and Interaction Analysis. The 3D structure of C7 was predicted by Pepfold3. As shown in Fig. 10A, C7 forms a random coil configuration. To illuminate the binding mode of peptides, peptide $\mathrm{C} 7$ and FR $\alpha$ protein were uploaded to ClusPro server for molecular docking respectively. The most favorable models from the 29 server retrieved complexes were chosen for further research. The interactions between FR $\alpha$ and peptide from the molecular docking were analyzed by MOE. The peptide-FR $\alpha$ complex and folate-FR $\alpha$ complex (PDB ID: 4LRH) were overlapped respectively. FR $\alpha$ has a globular structure stabilized by eight disulfide bonds and contains a deep open folate-binding pocket. Peptide C7, because of its size, cannot stick into the pocket, but binds with FR $\alpha$ close at the entrance of the pocket. C7 forms hydrogen bonds with Tyr60, Ser101, and Trp138 as a H-donor and as a H-acceptor forms five hydrogen bonds with Lys19, Arg61, Trp102, Lys136, and Gly137 (Fig. 10B). In addition, C7 can make a H- $\pi$ interaction with Trp140.

\section{Discussion}

In this manuscript, we conduct a research to discover tumor targeting peptides using phage display. We performed 4 rounds of screening. In the first 3 rounds, the phage yield and polyclonal ELISA signal both increased, indicating the enrichment of FR $\alpha$ binding phage. However, in the fourth round of selection, the yield and polyclonal ELISA value decreased, suggesting that the eluted pool of phage was fully enriched in favor of binding sequences after 3 rounds. Once this point is reached, further rounds of amplification and panning would result only in selection of phages that have a growth advantage over the library phages. Therefore, individual clones were picked from the third round biopanning for further studied. Interestingly, among the selected peptide sequence, Met-His-Thr-Ala-Pro-Gly-Trp-Gly-Tyr-Arg-Leu-Ser has been isolated repeatedly in our laboratory on different targets and was identified as a polystyrene binding peptide ${ }^{24}$. 

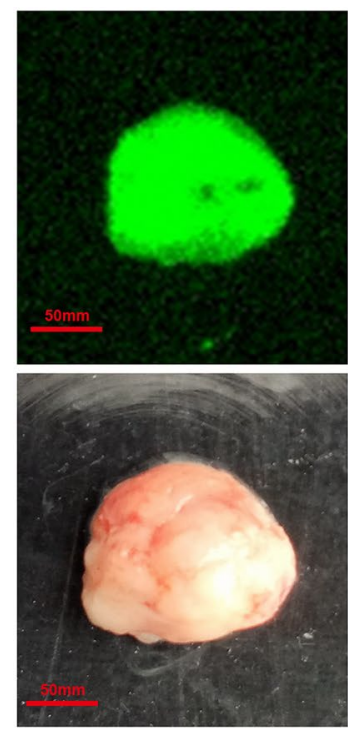

Tumor
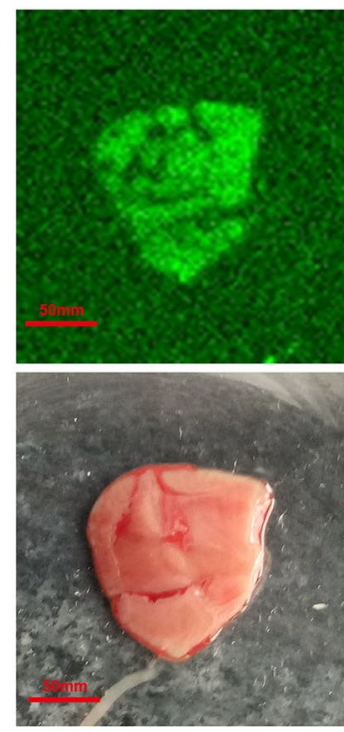

Liver
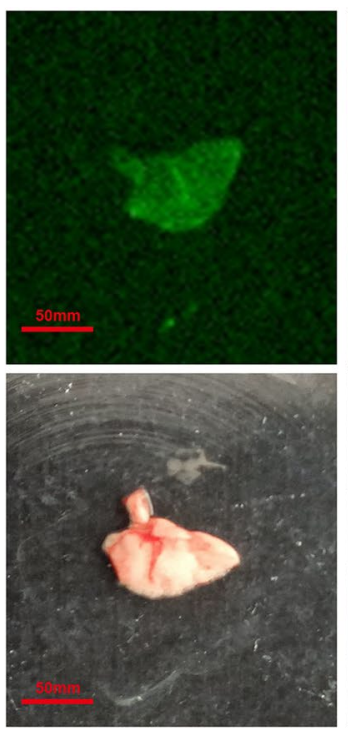

Lung
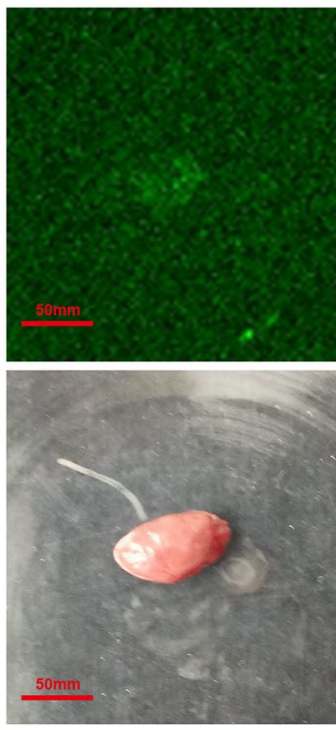

Heart
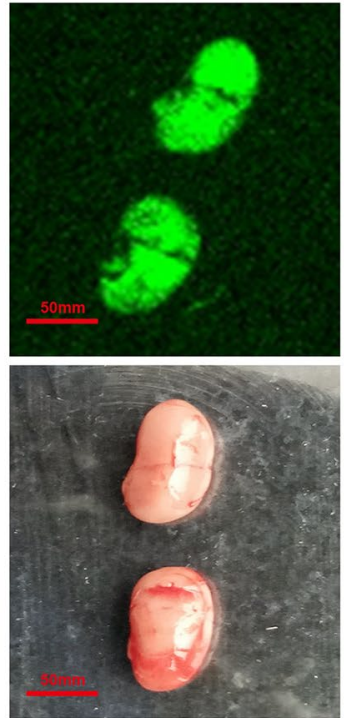

Kidney
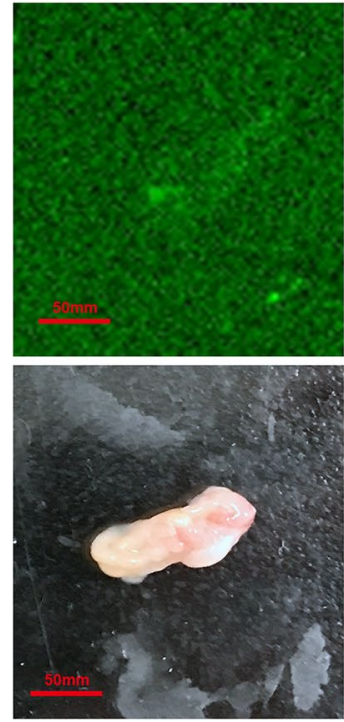

Ovary

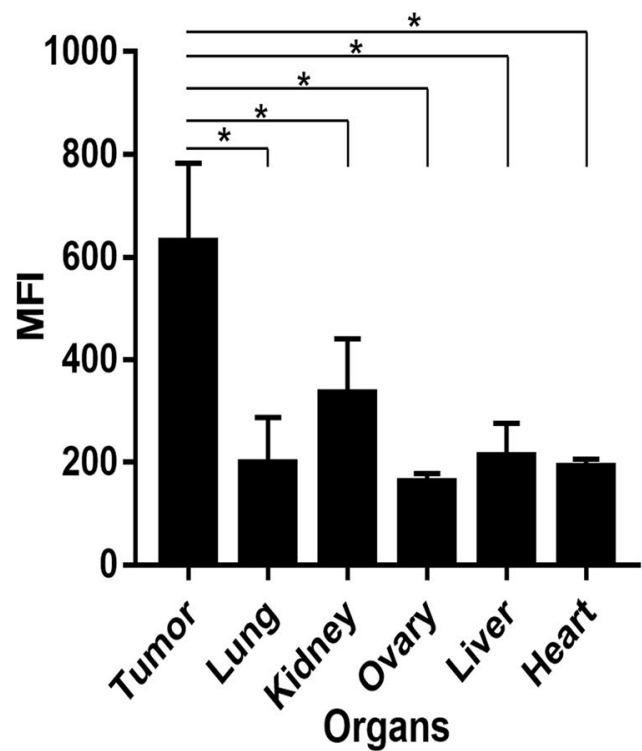

Figure 6. The tumor-targeting efficacy of synthetic peptides in vivo. FITC conjugated peptide C7 was chemically synthesized with more than $95 \%$ purity. The peptide was dissolved in PBS and injected intravenously into a tumor bearing nude mouse $(200 \mu \mathrm{L}, 10 \mathrm{mg} / \mathrm{mL})$. After 2 hours circulation, the fluorescence distributions in tumor and other organ tissues were analyzed with Carestream IS4000 fluorescence imaging system. Data were given as the mean $\pm \mathrm{SD}(\mathrm{n}=3)$.

Taking into consideration of the difference between the prokaryotic expressed FR $\alpha$ protein and eukaryotic mammal cell surface $\mathrm{FR} \alpha$, the 15 different peptide sequences were screened further by a cell based ELISA. Predicatively, not all the clones bind to SKOV3 cells as well as to FR $\alpha$ protein. Also, a few clones were excluded because of their unspecific binding to HepG2 cells without FR $\alpha$ expression. In flow cytometry, phage clone C7 was confirmed its highest binding to SKOV3 cells and was chosen for an ensuing study. In tumor bearing nude mouse model, the selected phage $\mathrm{C} 7$ was validated for its tumor targeting ability by in vivo homing experiment.

FITC conjugated peptide C7 was synthesized and studied. The fluorescence group might affect the binding ability of the molecule to be conjugated. By computational docking analysis, we found that amino acids at $\mathrm{N}$-terminus of $\mathrm{C} 7$ contribute little to the interaction with $\mathrm{FR} \alpha$, while amino acids at the C-terminus form more stable hydrogen bonds with FR $\alpha$ (Fig. 10B). Therefore, the FITC was conjugated to $\mathrm{N}$ - terminal of the peptides. To study whether the peptide really binds to FR $\alpha$, we employed RNA interference to specifically knockdown FR $\alpha$ expression in SKOV3 cells. We observed that the binding of C7 peptide was decreased significantly after FR $\alpha$ silencing. This experiment confirmed that C7 peptide binds to SKOV3 cells through FR $\alpha$. In this study we aimed to discover a tumor targeting peptide and the FITC conjugated peptide was used to evaluate the tumor-targeting 


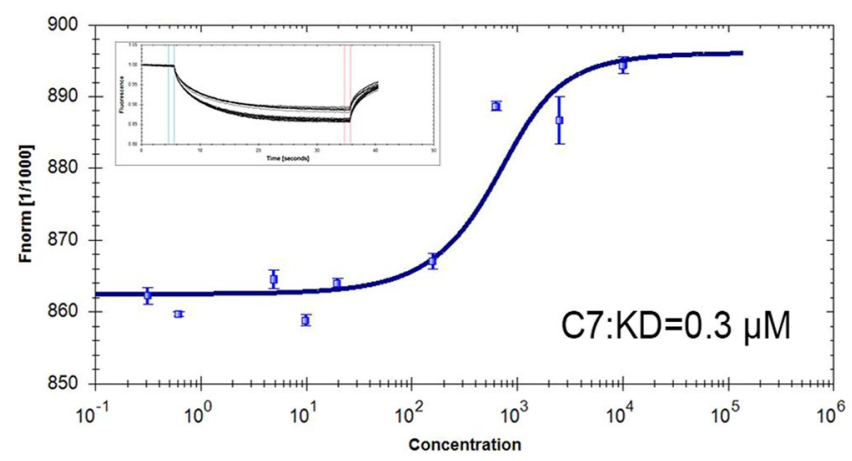

Figure 7. Affinity test. FITC conjugated peptide C7 was diluted with PBS. Serial dilutions of peptide were mixed with purified FR $\alpha$ protein $(1 \mu \mathrm{g} / \mathrm{mL})$ and incubated for $5 \mathrm{~min}$ at room temperature. Each sample was loaded into the standard monolith NT capillary and detected in Monolith NT.115. The error bars reflect standard deviation (SD) from 3 measurements.

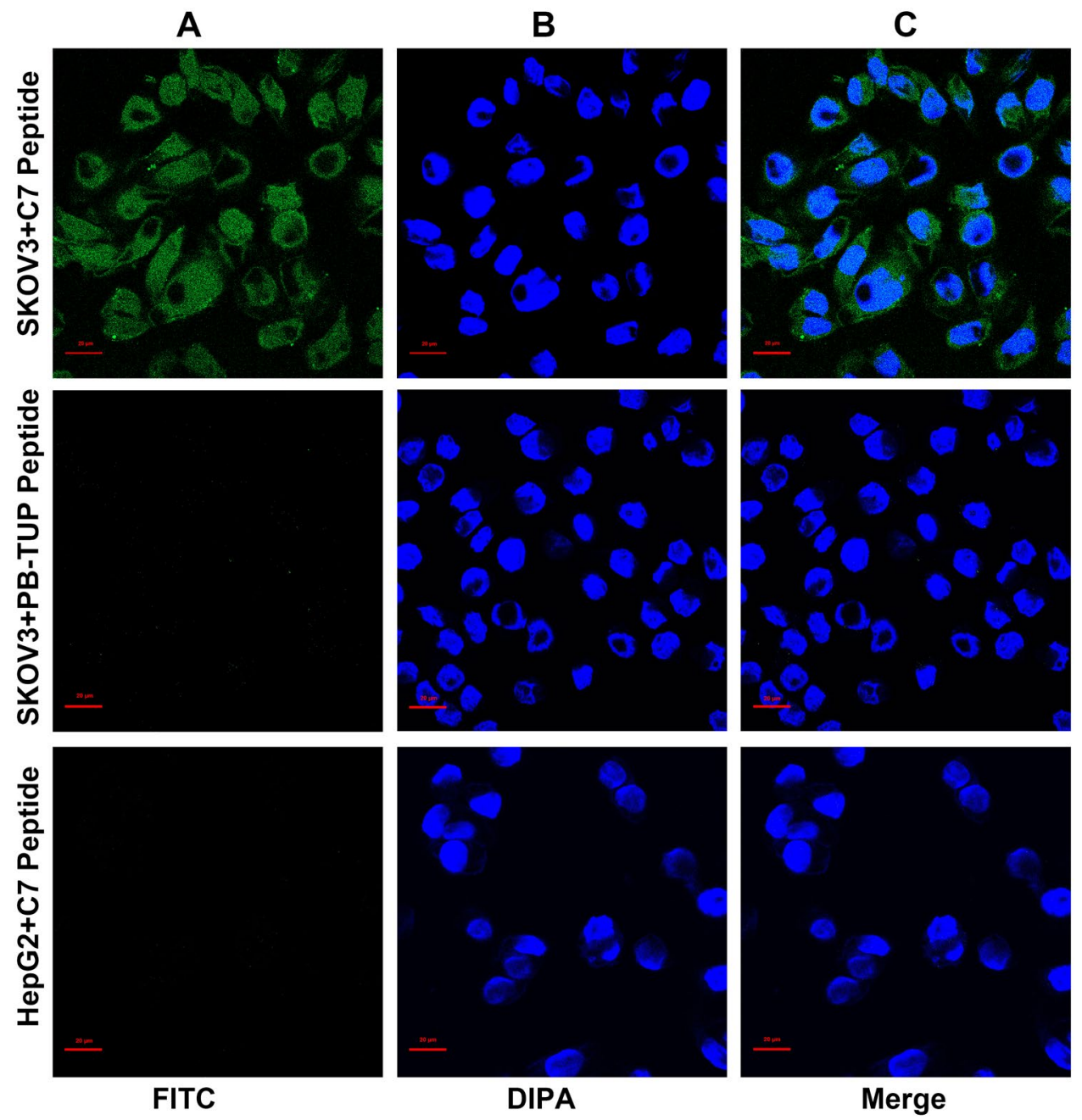

Figure 8. Cell internalization. FITC conjugated peptide $\mathrm{C} 7$ or was incubated with SKOV3 cells for 4 hours at $37^{\circ} \mathrm{C}$. Then the cells were washed, fixed and stained with DAPI and viewed by confocal microscopy. (A) FITC conjugated C7. (B) DAPI stained SKOV3 nuclei. (C) Overlay of A and B showing that the C7 is internalized.

ability in vivo and the result showed that except for the liver and kidney, C7 was accumulated at the site of tumor tissue, indicating that the peptide has the ability to target tumor tissue without phage environment. The FITC conjugates peptide can also be internalized into cells. The result is encouraging as it suggests that the peptide 


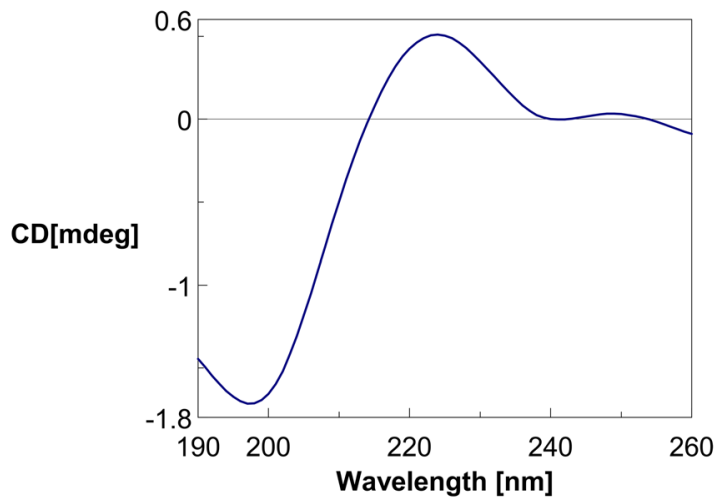

Figure 9. Circular dichroism spectrum of the synthesized peptide C7. The peptide solution $(0.3 \mathrm{mg} / \mathrm{mL})$ was prepared using ultra water. Spectra were collected every $1 \mathrm{~nm}$ from 260 to $190 \mathrm{~nm}$. The CD spectra are recorded as $\mathrm{CD}$ (mdeg).
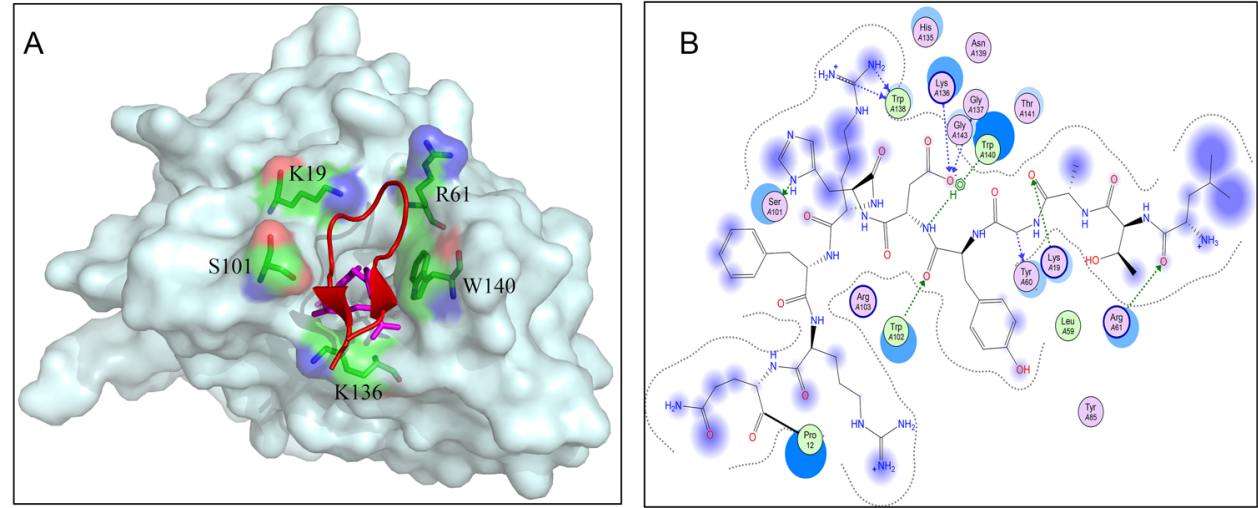

C. Ligand Interaction Report

\begin{tabular}{|lllllllll|}
\hline \multicolumn{2}{l}{ Ligand } & \multicolumn{2}{l}{ Receptor } & & & Interaction & Distance & E (kcal/mol) \\
CA & 27 & O & TYR & 60 & (A) & H-donor & 3.22 & -0.8 \\
ND1 & 58 & OG & SER & 101 & (A) & H-donor & 2.86 & -2.6 \\
NH1 & 74 & O & TRP & 138 & (A) & H-donor & 2.78 & -3.7 \\
NH2 & 77 & O & TRP & 138 & (A) & H-donor & 2.62 & -4.3 \\
O & 9 & NH2 & ARG & 61 & (A) & H-acceptor & 2.70 & -4.6 \\
0 & 24 & NZ & LYS & 19 & (A) & H-acceptor & 2.83 & -10.5 \\
O & 43 & NE1 & TRP & 102 & (A) & H-acceptor & 2.71 & -2.4 \\
OD2 & 50 & CA & LYS & 136 & (A) & H-acceptor & 3.51 & -1.2 \\
OD2 & 50 & N & GLY & 137 & (A) & H-acceptor & 3.18 & -5.4 \\
N & 44 & 6-ring & TRP & 140 & (A) & H-pi & 4.68 & -0.8 \\
\hline
\end{tabular}

Figure 10. Binding mode of peptide to FR $\alpha$ by molecular docking. (A) Overlay of the crystal structures of C7-FR $\alpha$ complexes and folate-FR complexes (4LRH). (B) 2D interaction of C7 and FR $\alpha$. (C) Ligand interactions report.

might be an appropriate carrier not only for targeting tumor cells but also for delivery of cytotoxic drugs into the cells. Further investigations in the future are planned to define the internalization mechanism of the peptides.

By computational docking, we analyzed the interaction between the peptide and FR $\alpha$. In this computer model, the peptide binds at the entrance of the folate binding pocket, but does not stick into the pocket. C7 interacts with Tyr60, Arg61, Ser101, Lys19, Trp102, Lys136, Gly137 and Trp140 of FR $\alpha$. Some of these amino acids (Tyr60, Trp102, Lys136, Gly137, and Trp140) also interact with the glutamate group of folate at the entrance of the folate-binding pocket. However, these amino acids do not play important role in binding with folate because mutations of these amino acids did not abolish the expression level of FR $\alpha$ or decrease the affinity between FR $\alpha$ and folate ${ }^{19}$. Typ171 and Asp81, which locate inside the folate binding pocket, interact with the pterin ring of folate and are considered as key contributors to high-affinity folate binding ${ }^{19}$. However, they do not interact with the peptide $\mathrm{C} 7$ on our binding model. The peptide, because of the size, cannot dock into the folate binding pocket but binds to the surface of the receptor. This different binding mode may explain its relatively weak binding to 
FR $\alpha$ with a KD value of $0.3 \mu \mathrm{M}$. In general, the affinity of peptide is lower compared to antibodies. Different strategies can be employed to improve the affinity of C7. One strategy is to change the stereochemistry of a peptide. For example, a D-amino acid peptide ligand showed a 10-fold improvement in affinity compared to its L-amino acid counterpart ${ }^{25}$. Another strategy is dimerization or trimerization of a peptide. After dimerization, the affinity a PSMA-specific peptide was dramatically enhanced ${ }^{26}$. In our future studies, we will begin with dimerization to improve the binding affinity of $\mathrm{C} 7$.

Most residues involved in folate binding are identical among different subtypes, indicating that the folate binding interactions are probably conserved in all three different folate receptor subtypes. Unlike anti-FR $\alpha$ antibodies, folate conjugates target both FR $\alpha$ and the functional form of FR $\beta$ and this might reduce the selectivity for tumor cells. It is interesting to be indicated by computational docking that the peptide $\mathrm{C} 7$ form hydrogen bond with R61, which is a unique amino acid at the entrance of folate binding pocket in FR $\alpha$ but not present in other folate receptor subtypes (Supplementary Fig. S1). This unique binding give rise to the hypothesis that the peptide C7 may target FR $\alpha$ specifically without affecting FR $\beta$, avoiding the possible adverse effects of the folate conjugates. Further experimental works are still needed to prove this hypothesis.

\section{Conclusion}

In conclusion, we have discovered and characterized C7 as a potent and selective peptide ligand for FR $\mathrm{F}$. C7 showed specific binding to FR $\alpha$ expression cells and tumor targeting ability in vivo. This peptide can be internalized into SKOV3 cells and the affinity for FR $\alpha$ is around $0.3 \mu \mathrm{M}$. As a tumor-specific peptide ligand, C7 has great potential for delivery of cancer therapeutics or imaging agents to FR $\alpha$ expressing tumors.

\section{Materials and Methods}

Library Screening. Recombinant folate receptor $\alpha$ was expressed in E. coli system and purified with a $\mathrm{Ni}$-column. The purified recombinant protein was dissolved in carbonate buffer ( $\mathrm{pH} 9.6)$ and coated on polystyrene 96-well microtiter plates (Corning, Inc., NY, USA) overnight at $4{ }^{\circ} \mathrm{C}$ at a concentration of $50 \mu \mathrm{g} / \mathrm{mL}, 100 \mu \mathrm{L}$ per well. The next day, each well was blocked with $200 \mu \mathrm{L} 3 \%$ (w/v) bovine serum albumin (Sangon Biotech Co., Ltd., Shanghai) dissolved in $0.01 \mathrm{M}$ TBS (pH 7.4) for 2 hours at $37^{\circ} \mathrm{C}$. After washing 3 times with TBS containing $0.05 \%$ (v/v) Tween 20 (TBST), $100 \mu \mathrm{L}$ Ph.D.-12 peptide library aliquot (New England Biolabs, Inc., USA) containing $10^{11}$ phages was added to each well and the plate was incubated for 1 hour at $37^{\circ} \mathrm{C}$. After washing 10 times with TBST and 3 times with TBS to remove the unbound phages, the target-bound phages were eluted with $150 \mu \mathrm{L} 100 \mathrm{mM}$ Glycine- $\mathrm{HCl}(\mathrm{pH} 2.2)$ and neutralized immediately with $9 \mu \mathrm{L} 2 \mathrm{M}$ Tris- $\mathrm{HCl}(\mathrm{pH}$ 9.1). $5 \mu \mathrm{L}$ of eluate was used for titering and the rest was used to infect E. coli ER2738 host strain (New England Biolabs, Inc., USA) for amplification. Phage particles were rescued from the cells and used for the subsequent round of target selection. The rescue-selection-plating cycle was repeated 4 times with reduced concentration of coating protein. Polyclonal phage ELISA was performed to evaluate the enrichment of FR $\alpha$ binding phage after each round screening. 94 individual clones were analyzed for specific antigen binding by phage ELISA. Phage titer and amplification was performed as previously described ${ }^{24}$. Phage recovery rate of each round was calculated as: titer of output phage/titer of input phage $\times 100 \%$.

Phage ELISA Assay. 96-well microtiter plates were coated with $100 \mu \mathrm{L} 10 \mu \mathrm{g} / \mathrm{mL}$ recombinant FR $\alpha$ in $0.05 \mathrm{M}$ sodium bicarbonate ( $\mathrm{pH} 9.6$ ) and the plate was kept overnight at $4^{\circ} \mathrm{C}$. After washing the plate three times with TBST, the plate was blocked with $3 \%$ BSA at $37^{\circ} \mathrm{C}$ for $2 \mathrm{~h}$. For polyclonal phage ELISA, after each round of screening, the phage eluate was amplified and $100 \mu \mathrm{L} 10^{10}$ phages diluents were added to each well and incubated for $2 \mathrm{~h}$. To analysis individual phage clones, each phage clone was amplified and $10^{10}$ phages were added to each well $\left(100 \mu \mathrm{L} /\right.$ well) and incubated for 2 hours at $37^{\circ} \mathrm{C}$. After washing the plate for 3 times with TBST and 3 times with TBS, $100 \mu \mathrm{L}$ of HRP-conjugated anti-M13 antibody (1:10000, Sino Biological, Inc., Beijing) was added and the plate was incubated for 1 hour at $37^{\circ} \mathrm{C}$. After washing, the tetramethylbenzidine (TMB) (Sangon Biotech Co., Ltd., Shanghai) substrate $(100 \mu \mathrm{L} /$ well $)$ was added to the wells and the reaction lasted for 15 minutes. The reactions were stopped with $2 \mathrm{M}$ sulfuric acid $(50 \mu \mathrm{L} /$ well). The absorbance of each well at $450 \mathrm{~nm}$ was detected with an automated ELISA reader.

Cell-based ELISA. Phage clones with high ELISA value were further tested by cell-based ELISA. SKOV3 (human epithelial ovarian cancer cell) is a FR $\alpha$ expressing cell line and was used to evaluate the binding of selected phage clones to natural FR $\alpha$ protein on cell surface. HEPG2 (Human Liver Carcinoma Cell) without FR $\alpha$ expressing was used as a negative control. Both cell lines were purchased from Shanghai Cell Biology Institutes (Academia Sinica, Shanghai, China) and maintained in RPMI 1640 Medium with $10 \%$ fetal bovine serum and antibiotics. The presence or absence of FR $\alpha$ expression of the two cell lines were confirmed by flow cytometry described in 2.4 . The cells were cultured in 96 -well plate to $80 \%$ confluence and fixed with $4 \%$ paraformaldehyde. After blocking with $3 \%$ BSA for $2 \mathrm{~h}, 10^{10}$ individual phages were added to each well and incubated at $37^{\circ} \mathrm{C}$ for $2 \mathrm{~h}$. Then the plate was washed with PBST for three times and cell-bound phage was detected with HRP-conjugated anti-M13 IgG (1:10000) as described in phage ELISA.

Flow Cytometry. SKOV3 and HEPG2 were tested individually for their expression of FR $\alpha$. The cells were collected and suspended in $2 \%$ FCS-PBS medium at $1 \times 10^{6}$ cells $/ \mathrm{mL}$ and incubated with polyclonal anti-FR $\alpha$ antibody (1:1000, Sino Biological, Inc., Beijing) at $4^{\circ} \mathrm{C}$ for $1 \mathrm{~h}$. After washing the cells twice with $2 \%$ FCS-PBS by 5 min centrifugation at $300 \mathrm{~g}$, the cells were stained for $30 \mathrm{~min}$ at $4^{\circ} \mathrm{C}$ with AF647 conjugated goat anti-mouse antibody (Fcmacs, Inc., Nanjing). Cells were subjected to fluorescence analysis using a flow cytometry analyzer (Guava ${ }^{\circledR}$ easyCyte 6-2 L, MilliporeSigma, USA).

SKOV 3 cells were collected and suspended in $2 \%$ FCS-PBS medium at $1 \times 10^{6}$ cells $/ \mathrm{mL}$. Purified phage clones were incubated individually with the cells at $4^{\circ} \mathrm{C}$ for $1 \mathrm{~h}$. The cells were washed twice with $2 \%$ FCS-PBS by 5 min 
centrifugation at $300 \mathrm{~g}$. Mouse anti-M13 antibody was diluted with 2\% FCS-PBS (1:400) and incubated with cells for $30 \mathrm{~min}$ at $4{ }^{\circ} \mathrm{C}$. After washing, the cells were stained for $30 \mathrm{~min}$ at $4{ }^{\circ} \mathrm{C}$ with FITC conjugated goat anti-mouse antibody (Fcmacs, Inc., Nanjing). Cells were analyzed as described above.

FR $\alpha$ knockdown by RNA interference. FR $\alpha$ targeting siRNA (sense: GGACUGAGCUUCUCAAUGUTT, antisense: ACAUUGAGAAGCUCAGUCCTT) and the control siRNA (sense: UUCUCCGAACGUGUCACGUTT, antisense: ACGUGACACGUUCGGAGAATT) were designed and synthesized by Shanghai Genepharma RNAi company. SKOV3 cells were cultured in 6-well plate to 70\% confluence and the siRNA were transfected into SKOV3 cells using SuperFectin siRNA Transfection Reagent (Pufei Biological, Inc., ShangHai). After 72 h, siRNA mediated silencing of FR $\alpha$ was tested with monoclonal anti-FR $\alpha$ antibody (1:1000, Sino Biological, Inc., Beijing) using flow cytometry and the binding of C7 peptide to SKOV3 with or without RNA interference was analyzed.

In Vivo Homing Study of Phage Clones. Female Balb/c nude mice aged 6-8 weeks were purchased from the Yangzhou University Animal Center. All the animal studies were performed in compliance with the National Institutes of Health Guide for the Care and Use of Laboratory Animals and approved by IACUC (Institutional Animal Care and Use Committee of China Pharmaceutical University). The authors confirm that experiments involving laboratory animals adhered to the ethical standards of National Institutes of Health Guide and China Pharmaceutical University. The laboratory animals were used under the experimental animal production license 2121922. All animals were housed in a controlled environment $\left(25^{\circ} \mathrm{C} ; 12 \mathrm{~h}\right.$ light-dark cycle), with water and food provided freely. $2 \times 10^{6} \mathrm{SKOV} 3$ cells were subcutaneously injected into the left flank of mice to generate epithelial ovarian cancer xenografts. $2 \times 10^{11}$ individual purified phage clones were injected intravenously and circulated for $15 \mathrm{~min}$. After anesthetized with $10 \mathrm{mg} / \mathrm{kg}$ chloroquine $(5 \% \mathrm{w} / \mathrm{v})$, the mice were perfused through the heart. Then, the tumor and main organs (liver, lung, kidney, heart and ovary) were harvested, weighed and homogenated. The homogenated tissues were washed, and lysed with $1 \%$ NP40. Bound phages were recovered by elution and titrated as described ${ }^{24}$. The distribution of phages was calculated as phages per gram.

Tumor Targeting of Conjugated Synthetic Peptides. FITC conjugated peptide C7 was chemically synthesized by GL Biochem (Shanghai, China) and purified by high-performance liquid chromatography with more than $95 \%$ purity and confirmed by mass spectrometry. The FITC conjugated peptide was evaluated in tumor bearing mice for its tumor targeting capability. The peptide was dissolved in PBS at a concentration of $10 \mathrm{mg} / \mathrm{mL}$ and $200 \mu \mathrm{L}$ was injected intravenously into a tumor bearing nude mouse. After $2 \mathrm{~h}$ circulation, tumor and other organ tissues (liver, lung, kidney, heart, and ovary) were harvested and analyzed using Carestream IS4000 fluorescence imaging system.

Affinity test using Microscale Thermophoresis (MST). FITC conjugated peptide C7 was diluted with PBS, pH 7.4. Serial dilutions of peptide were mixed with purified FR $\alpha$ protein $(1 \mu \mathrm{g} / \mathrm{mL})$ and incubated for $5 \mathrm{~min}$ at room temperature. Each sample was loaded into the standard monolith NT capillary and detected in Monolith NT.115. According to the changes of fluorescent thermophoresis signal caused by the serial concentrations, the equilibrium dissociation constant (KD) value was calculated from Hill formula by the NT analysis software.

Cell internalization of Synthesized Peptide C7. To visualize internalization of synthesized peptide C7 into cells, SKOV3 or HepG2 cells were seeded in 24 well plates ( $10^{5}$ cells/well) containing coverslips and incubated for 24 hours in RPMI 1640 medium with 10\% FBS. FITC conjugated peptide C7 or PB-TUP ${ }^{24}$ (VHWDFRQWWQPS) $(200 \mu \mathrm{g} / \mathrm{mL})$ was incubated with the cells for 4 hours at $37^{\circ} \mathrm{C}$. After incubation, the cells were washed once with PBS and fixed in $4 \%$ paraformaldehyde for $10 \mathrm{~min}$. Cells were then washed three times with PBS and stained with DAPI for $20 \mathrm{~min}$ at room temperature. Internalized fluorescent signals were imaged with a Zeiss LSM800 confocal microscope.

Circular Dichroism Spectroscopy. Circular dichroism (CD) spectroscopy was performed on a Jasco J-810 spectropolarimeter using a $1-\mathrm{mm}$ cuvette. The peptide was dissolved in ultrapure water at a concentration of $0.3 \mathrm{mg} / \mathrm{mL}$. Spectra were collected every $1 \mathrm{~nm}$ from 260 to $190 \mathrm{~nm}$. The CD spectra are reported as CD (mdeg).

Molecular Docking and Molecular Dynamics Stimulation. The 3D structures of C7 peptide were predicted by Pepfold3, a peptide structure prediction server. It predicts the structure of peptide based on the Hidden Markov model conformation sampling approach ${ }^{27}$. The peptide sequence was imported into the workspace of Pepfold3 and allowed to run. Predicted 3D structure was noted in PDB format. The crystal structure of folate receptor $\alpha$ was obtained from the Protein Data Bank (www.rcsb.org) (PDB ID: 4LRH), and then the ligand folate was extracted as a docking receptor. Interaction between peptide and folate receptor $\alpha$ was analyzed by applying ClusPro protein-protein molecular docking programme ${ }^{28-31}$. ClusPro's docking algorithms calculated the billions of values for putative complexes and determined a reset number with favorable surface complementarities ${ }^{30,32}$. In the docking analysis, top-docked complex was detected and assessed by molecular dynamics (MD) simulation in order to refine and validate the protein interface. MD simulation was performed using the GROMACS package v.4.5.5. The interface of interactions was analyzed with MOE 2014.09. The high-quality images of molecular models of the complexes were rendered using Pymol.

Statistical analysis. All statistical analyses were performed by using GraphPad Prism 6.0 software (GraphPad software Inc., San Diego, CA, USA). Unpaired two-tailed student's t-test was used to analyze the differences between means. All data are expressed as the mean $\pm \mathrm{SD}$. The error bars represent the standard deviation of three independent determinations. Asterisks indicate significant level versus the control condition: $* \mathrm{P}<0.05$, $* * \mathrm{P}<0.01, * * * \mathrm{P}<0.001$. 


\section{References}

1. Henderson, G. B. Folate-Binding Proteins. Annual Review of Nutrition 10, 319-335, https://doi.org/10.1146/annurev.nu.10.070190. 001535 (1990).

2. Ross, J. F., Chaudhuri, P. K. \& Ratnam, M. Differential regulation of folate receptor isoforms in normal and malignant tissues in vivo and in established cell lines. Physiologic and clinical implications. Cancer-Am Cancer Soc 73, 2432-2443, doi:10.1002/10970142(19940501)73:9<2432::AID-CNCR2820730929>3.0.CO;2-S (1994).

3. Matsue, H. et al. Folate Receptor Allows cells to Grow in Low Concentrations of 5-Methyltetrahydrofolate. P Natl Acad Sci USA 89, 6006-6009, https://doi.org/10.1073/pnas.89.13.6006 (1992).

4. Kelemen, L. E. The role of folate receptor alpha in cancer development, progression and treatment: Cause, consequence or innocent bystander? Int J Cancer 119, 243-250, https://doi.org/10.1002/ijc.21712 (2006).

5. Kane, M. A. et al. Influence on immunoreactive folate-binding proteins of extracellular folate concentration in cultured human cells. The Journal of clinical investigation 81, 1398-1406, https://doi.org/10.1172/jci113469 (1988).

6. Bueno, R., Appasani, K., Mercer, H., Lester, S. \& Sugarbaker, D. The alpha folate receptor is highly activated in malignant pleural mesothelioma. Journal Of Thoracic And Cardiovascular Surgery 121, 225-233, https://doi.org/10.1067/mtc.2001.111176 (2001).

7. Hartmann, L. C. et al. Folate receptor overexpression is associated with poor outcome in breast cancer. Int J Cancer 121, 938-942, https://doi.org/10.1002/ijc.22811 (2007).

8. Cheung, A. et al. Targeting folate receptor alpha for cancer treatment. Oncotarget 7, 52553-52574, https://doi.org/10.18632/ oncotarget.9651 (2016)

9. Josephs, D. H. et al. Anti-Folate Receptor- $\alpha$ IgE but not IgG Recruits Macrophages to Attack Tumors via TNF $\alpha /$ MCP-1 Signaling. Cancer Res 77, 1127-1141, https://doi.org/10.1158/0008-5472.can-16-1829 (2017).

10. Leamon, C. P. \& Reddy, J. A. Folate-targeted chemotherapy. Advanced drug delivery reviews 56, 1127-1141, https://doi.org/10.1016/j. addr.2004.01.009 (2004).

11. Leamon, C. P. et al. Preclinical antitumor activity of a novel folate-targeted dual drug conjugate. Mol Pharmaceut 4, 659-667, https:// doi.org/10.1021/mp070049c (2007).

12. Qiu, Z. et al. CpG oligodeoxynucleotides augment antitumor efficacy of folate receptor $\alpha$ based DNA vaccine. Oncol Rep 37, 3441 (2017).

13. Ebel, W. et al. Preclinical evaluation of MORAb-003, a humanized monoclonal antibody antagonizing folate receptor-. Cancer Immun. 7, 6. Cancer Immunity A Journal of the Academy of Cancer Immunology 7, 6 (2007).

14. Kamen, B. A. \& Smith, A. K. Farletuzumab, an anti-folate receptor alpha antibody, does not block binding of folate or anti-folates to receptor nor does it alter the potency of anti-folates in vitro. Cancer Chemoth Pharm 70, 113-120, https://doi.org/10.1007/s00280012-1890-2 (2012)

15. Gibbs, D. D. et al. BGC 945, a novel tumor-selective thymidylate synthase inhibitor targeted to alpha-folate receptor-overexpressing tumors. Cancer Res 65, 11721-11728, https://doi.org/10.1158/0008-5472.can-05-2034 (2005).

16. Theti, D. S. et al. Selective delivery of CB300638, a cyclopenta g quinazoline-based thymidylate synthase inhibitor into human tumor cell lines overexpressing the alpha-isoform of the folate receptor. Cancer Res 63, 3612-3618 (2003).

17. Chen, C. et al. Structural basis for molecular recognition of folic acid by folate receptors. Nature 500, 486 (2013).

18. Vlieghe, P., Lisowski, V., Martinez, J. \& Khrestchatisky, M. Synthetic therapeutic peptides: science and market. Drug Discov Today 15, 40-56, https://doi.org/10.1016/j.drudis.2009.10.009 (2010).

19. Berggard, T., Linse, S. \& James, P. Methods for the detection and analysis of protein-protein interactions. Proteomics 7, 2833-2842, https://doi.org/10.1002/pmic.200700131 (2007).

20. Lauwereys, M. et al. Potent enzyme inhibitors derived from dromedary heavy-chain antibodies. Embo Journal 17, 3512-3520, https://doi.org/10.1093/emboj/17.13.3512 (1998).

21. Petrenko, V. A. \& Vodyanoy, V. J. Phage display for detection of biological threat agents. Journal Of Microbiological Methods 53, 253-262, https://doi.org/10.1016/s0167-7012(03)00029-0 (2003).

22. Kang, J. et al. A peptide derived from phage display library exhibits anti-tumor activity by targeting GRP78 in gastric cancer multidrug resistance cells. Cancer Letters 339, 247-259, https://doi.org/10.1016/j.canlet.2013.06.016 (2013).

23. Bábíčková, J., Tóthová, L., Boor, P. \& Celec, P. In vivo phage display-a discovery tool in molecular biomedicine. Biotechnology Advances 31, 1247 (2013).

24. Qiang, X. et al. Discovery of a polystyrene binding peptide isolated from phage display library and its application in peptide immobilization. Sci Rep-Uk 7, 2673 (2017).

25. Zhou, N. et al. Exploring the stereochemistry of CXCR4-peptide recognition and inhibiting HIV-1 entry with D-peptides derived from chemokines. J Biol Chem 277, 17476 (2002).

26. Aggarwal, S., Singh, P., Topaloglu, O., Isaacs, J. T. \& Denmeade, S. R. A dimeric peptide that binds selectively to prostate-specific membrane antigen and inhibits its enzymatic activity. Cancer Res 66, 9171-9177 (2006).

27. Shen, Y., Maupetit, J., Derreumaux, P. \& Tufféry, P. Improved PEP-FOLD Approach for Peptide and Miniprotein Structure Prediction. Journal of Chemical Theory \& Computation 10, 4745 (2014).

28. Kozakov, D. et al. The ClusPro web server for protein-protein docking. Nature Protocols 12, 255 (2017)

29. Comeau, S. R., Gatchell, D. W., Vajda, S. \& Camacho, C. J. ClusPro: an automated docking and discrimination method for the prediction of protein complexes. Bioinformatics 20, 45 (2004).

30. Kozakov, D., Brenke, R., Comeau, S. R. \& Vajda, S. PIPER: an FFT-based protein docking program with pairwise potentials. Proteinsstructure Function \& Bioinformatics 65, 392-406 (2006).

31. Comeau, S. R., Gatchell, D. W., Vajda, S. \& Camacho, C. J. ClusPro: a fully automated algorithm for protein-protein docking. Nucleic Acids Research 32, 96-99 (2004).

32. Shen, Y., Ich, P., Vakili, P. \& Vajda, S. Protein Docking by the Underestimation of Free Energy Funnels in the Space of Encounter Complexes. Plos Computational Biology 4, e1000191 (2008).

\section{Acknowledgements}

The present study was supported by the National Natural Science Foundation of China (Grant No. 81301902 and 81773837) and Priority Academic Program Development of Jiangsu Higher Education Institutions (PAPD).

\section{Author Contributions}

Z.Q., M.W. and J.Z. designed this study. L.J.X. and Z.P.Z. performed the biopanning by phage display and carried out the ELISA analyses. Y.F.X. and H.W. prepared the proteins for target screening. L.J.X., Y.F.X. and F.G.Z. conducted the animal experiments and analyzed the data. K.Y.S. performed the molecular modelling. F.Z. performed flow cytometry experiment. L.J.X. and Y.F.X. performed RNA interfering. All of the authors discussed the results. Z.Q. and L.J.X. Wrote the manuscript with help from the other authors. B.C. modified the manuscript.

Additional Information

Supplementary information accompanies this paper at https://doi.org/10.1038/s41598-018-26683-z. 
Competing Interests: The authors declare no competing interests.

Publisher's note: Springer Nature remains neutral with regard to jurisdictional claims in published maps and institutional affiliations.

(c) (i) Open Access This article is licensed under a Creative Commons Attribution 4.0 International License, which permits use, sharing, adaptation, distribution and reproduction in any medium or format, as long as you give appropriate credit to the original author(s) and the source, provide a link to the Creative Commons license, and indicate if changes were made. The images or other third party material in this article are included in the article's Creative Commons license, unless indicated otherwise in a credit line to the material. If material is not included in the article's Creative Commons license and your intended use is not permitted by statutory regulation or exceeds the permitted use, you will need to obtain permission directly from the copyright holder. To view a copy of this license, visit http://creativecommons.org/licenses/by/4.0/.

(c) The Author(s) 2018 